\title{
Glycemic, Insulinemic, Lipidemic and Antioxidant Status of nSTZ Rats after Chronic Administration of Cicer arietinum Extract
}

\author{
Amrita Bhowmik ${ }^{1}$, Mossihuzzaman $\mathrm{M}^{2,3}$, Yearul Kabir ${ }^{4}$ and Begum Rokeya ${ }^{5 *}$ \\ ${ }^{1}$ Department of Applied Laboratory Sciences, Bangladesh University of Health Sciences (BUHS), Bangladesh \\ ${ }^{2}$ Department of Chemistry, Bangladesh University of Health Sciences (BUHS), Bangladesh \\ 3 International Centre for Natural Product Research (ICNPR), Bangladesh \\ ${ }^{4}$ Biochemistry and Molecular Biology, University of Dhaka, Bangladesh \\ ${ }^{5}$ Department of Pharmacology, Bangladesh University of Health Sciences (BUHS), Bangladesh
}

\begin{abstract}
Background: The aims of the study were to evaluate glycemic, insulinemic, lipidemic and antioxidant properties of C. arietinum in neonatal-streptozotocin (nSTZ) rats.
\end{abstract}

Materials and methods: Seeds were collected from the commercially available sources of Dhaka city, identified from Bangladesh National Herbarium and absolute ethanol extract was prepared. A single iv injection of STZ were given to neonate rats of Long Evans strain and 12 weeks later an OGTT was done and rats with fasting glucose level above $7.5 \mathrm{mmol} / \mathrm{L}$ were selected. The rats were divided into four groups: i) Water control, ii) Glibenclamide (5 mg/kg bw), iii) $C$. arietinum $0.625 \mathrm{~g} / \mathrm{kg}$ bw (CA Ext 1) and iv) $1.25 \mathrm{~g} / \mathrm{kg}$ bw (CA Ext 2) treated. Body weight was measured weekly. Blood was collected by cutting the tail tip on 0 day and by decapitation on 28 day. Fasting serum glucose, insulin, lipid profiles, creatinine, ALT, MDA, GSH, hepatic glycogen were measured. HOMA B\% and HOMA S\% were calculated. The data were analyzed using appropriate tools.

Results: A significant decrease of fasting glucose level was noticed on 28 day with CA Ext 2 compared to baseline $(p<0.05) ; 26 \%$ and $18 \%$ decrease were found in comparison to water and glibenclamide treated groups respectively. Blood glucose lowering effect was associated with insulin lowering effect of CA Ext 2. Treatment with CA Ext 2 improved HOMAB\%, and both treated groups improved HOMA IR of nSTZ diabetic rats. Total cholesterol was significantly decreased in comparison to water control on 28 day $(p=0.014)$; triglycerides decreased by $11 \%$ and $\mathrm{HDL}$ increased by $4 \%$ respectively in CA Ext 2 group. Serum ALT and creatinine levels were remained unchanged by $C$. arietinum. A significant increase of reduced-GSH level was found in CA Ext 1 treated group $(p=0.031)$.

Conclusion: CA Ext 2 showed significant hypoglycemic and antilipidemic effects most likely through decreasing insulin resistance and improving insulin sensitivity. It also has antioxidant activity that reduces the oxidative changes induced by STZ administration.

Keywords: Hyperglycemia; Diabetes; Lipids; Antioxidant; nSTZ; Cicer arietinum

\section{Abbreviations}

ALT: Amino Alanine Transferase; ANOVA: Analysis of Variance; BIRDEM: Bangladesh Institute of Research and Rehabilitation in Diabetes, Endocrine and Metabolic Disorders; FSG: Fasting Serum Glucose; GSH: Reduced Gluthathion; GOD-PAP: Glucose Oxidase; HOMA B\%: B cell secretion; HOMA S\%: Insulin sensitivity; HOMA IR: Insulin Resistance; HDL: High Density Lipoprotein; Nstz: neonatal Streptozotocin; OGTT: Oral Glucose Tolerance Test; MDA: Malondialdehyde; TG: Triglyceride; LDL: Low Density Lipoprotein; TBARS: Thiobarbituric Acid Reactive Substances; SPSS: Statistical Package for Social Science

\section{Introduction}

Hyperglycemia and hyperlipidemia are two important features of diabetes mellitus, an endocrine and metabolic disorder that has become the most challenging public health problem of the $21^{\text {st }}$ century. In modern medicine, no satisfactory effective therapy is still available to cure diabetes mellitus [1]. Diabetes management studies show that conventional antidiabetic agents like sulfonylureas are the least durable agents followed by metformin and thiazolidinediones. Therefore, search for improved antidiabetic drug has been continued. Over the last several years the incretin-based therapies have got significant importance although they are very much expensive especially for the people of the least developing countries. In recent years, there has been renewed interest in plant medicine for the treatment against different diseases as herbal drugs are generally believed to be less toxic as reported in different publications [2-6]. Many indeginous plant products, obtained from fruits, leaves, roots, bark etc. have been shown to possess multiple therapeutic properties like antidiabetic, antihyperlipidemic, antihypertensive, antioxidant, anticancer, antimicrobial, anti-inflammatory, analgesic and etc. [7-12]. Therefore, scientists are now focusing their attention on natural compounds to find, at least a lead, for antidiabetic agents. In this regard, carefully planned scientific research to identify the hypoglycemic plants with true therapeutic efficacy and safety is utmost needed inorder to develop them as new therapeutics.

Chickpea (Cicerarietinum L.) is an important pulse crop which is consumed all over the world, especially in the Afro-Asian countries. It is

*Corresponding author: Rokeya B, Department of Pharmacology, Bangladesh University of Health Sciences (BUHS), Bangladesh, Tel: +088-01711811350 E-mail: b_rokeya@yahoo.com

Received June 09, 2016; Accepted July 11, 2016; Published July 18, 2016

Citation: Bhowmik A, Mossihuzzaman M, Kabir Y, Rokeya B (2016) Glycemic Insulinemic, Lipidemic and Antioxidant Status of nSTZ Rats after Chronic Administration of Cicer arietinum Extract. Metabolomics (Los Angel) 6: 179. doi:10.4172/2153-0769.1000179

Copyright: @ 2016 Bhowmik A, et al. This is an open-access article distributed under the terms of the Creative Commons Attribution License, which permits unrestricted use, distribution, and reproduction in any medium, provided the original author and source are credited. 
Citation: Bhowmik A, Mossihuzzaman M, Kabir Y, Rokeya B (2016) Glycemic, Insulinemic, Lipidemic and Antioxidant Status of nSTZ Rats after Chronic Administration of Cicer arietinum Extract. Metabolomics (Los Angel) 6: 179. doi:10.4172/2153-0769.1000179

Page 2 of 7

considered as a good source of not only carbohydrates but also protein, and the quality of protein is better than other pulses. Chickpea has several potential health benefits and, in combination with other pulses and cereals, it could have beneficial effects on some of the important human diseases like cardiovascular disease, type 2 diabetes, digestive diseases and some cancers [13]. A significant antihyperglycemic activity of the chickpea have been reported in STZ induced diabetic rats $[14,15]$. The aims of the study were to evaluate glycemic, insulinemic, lipidemic and antioxidant properties of C. arietinum in neonatalstreptozotocin (nSTZ) diabetic rats.

\section{Place of Study}

The study was conducted in the Department of Pharmacology, Bangladesh Institute of Research and Rehabilitation in Diabetes, Endocrine and Metabolic Disorders (BIRDEM) and in the Department of Biochemistry and Molecular Biology, University of Dhaka, Bangladesh.

\section{Plant Material}

The dried matured seeds of $C$. arietinum were collected from the commercially available sources of Dhaka city. Seeds were identified by the taxonomist of Bangladesh National Herbarium, Dhaka (DACB Accession no 37757).

\section{Preparation of Ethanolic Extract of C. arietinum}

After collection, the matured dried seeds of C. arietinum were washed thoroughly and dried in the laboratory. Then the seeds were grinded to make fine powder by a grinding machine. The grinded powder was extracted by using absolute (96\%) ethanolic solvent. Following the completion of extraction, extract prepared from seeds of C. arietinum was concentrated under reduced pressure using a rotary evaporator (BUCHI R-114, Switzerland) maintained at $55^{\circ} \mathrm{C}$. The semidried ethanolic extract was further dried in a freeze drier (HETOSICC, Heto Lab Equipment, Denmark) at $-55^{\circ} \mathrm{C}$ and stored in a reagent bottle at $-8^{\circ} \mathrm{C}$ in a refregerator.

\section{Animals}

The Long Evans rats bred at Bangladesh Institute of Research and Rehabilitation in Diabetes, Endocrine and Metabolic Disorders (BIRDEM) animal house, were used in the study. The animals were maintained at a constant room temperature of $23^{\circ} \mathrm{C}$ with humidity of $40-70 \%$ and the natural 12 hours day-night cycle. The rats were fed on a standard laboratory pellet diet and water supplied ad libitum. The experiments were conducted according to the ethical guidelines approved by Bangladesh Association for Laboratory Animal Science.

\section{Preparation of Neonatal STZ (nSTZ) Diabetic Rats}

Diabetes was induced by a single intraperitoneal injection of streptozotocin (STZ) at a dose of $90 \mathrm{mg} / \mathrm{kg}$ body weight to the neonate rats (48 hours old) as described by Bonner-Weir et al. [16]. Following 3 months of STZ injection, rats were examined for their blood glucose level by oral glucose tolerance test (OGTT, Glucose $2.5 \mathrm{~g} / \mathrm{kg}$ bw). Diabetic model rats with blood glucose level $>7.00 \mathrm{mmol} / \mathrm{l}$, at fasting condition was selected for studying the effects of the extracts in chronic studies.

The experiment was carried out for duration of 28 days on 30 rats. Then STZ diabetic rats were divided into the following four groups:

1. Water Control group ( $n=7)$ : Treated with deionized water at a dose of $10 \mathrm{ml} / \mathrm{kg}$ bw.

2. Glibenclamide (positive) control group $(n=7)$ : Treated with glibenclamide at a dose of $5 \mathrm{mg} / / \mathrm{kg}$ bw.

3. CA Ext 1 treated group $(n=8)$ : Fed with ethanol extract of $C$. arietinum at a dose of $0.625 \mathrm{~g} / \mathrm{kg}$ bw.

4. CA Ext 2 treated group ( $n=8)$ : Fed with ethanol extract of $C$. arietinum at a dose of $1.25 \mathrm{~g} / \mathrm{kg}$ bw. Water, Glibenclamide and CA Ext $1 \& 2$ were administered intragastrically through metallic tubes to the corresponding group of rats after $12 \mathrm{hrs}$ fast.

\section{Collection of Blood Sample for Biochemical Analysis}

Blood samples were collected from rats kept under fasting conditions ( 12 hours) by amputation of the tail tip under diethyl ether anesthesia on the 0 day. On the $28^{\text {th }}$ day after 12 hours fast, blood was collected from the rats by cardiac puncture also under diethyl ether anesthesia. The collected blood samples were centrifuged at $2,500 \mathrm{rpm}$ for 15 minutes and finally the serums were separated into another eppendorf tubes for biochemical analysis. Two $\mathrm{mL}$ of blood was collected in heparinized tubes and then packed red cells were used for estimation of Malondialdehyde (MDA) and reduced Glutathione (GSH).

\section{Biochemical analysis}

Serum glucose was measured by Glucose Oxidase (GODPAP) method using micro-plate reader (Bio-Tec, ELISA); total cholesteroland Triglyceride (TG) by enzymatic colorimetric method (Randox Laboratories Ltd., UK), using autoanalyzer. LDL-cholesterol was calculated by Friedewald equation [17]. Serum insulin by (ELISA, Crystal Chem Inc., USA). HOMA B\% (Beta-cell function) and HOMA S\% (Insulin Sensitivity) were calculated by HOMA SIGMA Software [18]. HOMA IR (Insulin Resistance Index) were calculated by International Formula: fasting Glucose $(\mathrm{mmol} / \mathrm{L}) \times$ fasting Insulin $(\mathrm{mU} / \mathrm{L}) / 22.5$. Creatinine and Amino Alanine Transferase (ALT) by Auto-analyzer. Hepatic glycogen was measured by Anthrone-sulphuric acid method. Reduced Glutathione (GSH) and plasma Malondialdehyde (MDA) estimated by using Ellman's and Thiobarbituric Acid Reactive Substances (TBARS) method respectively $[19,20]$.

\section{Statistical analysis}

Data from the experiments were analyzed using the Statistical Package for Social Science (SPSS) software for windows version 12 (SPSS Inc., Chicago, Illinois, USA). All the data were expressed as Mean \pm SD as appropriate. Statistical analysis of the results was performed by using the student's $t$-test (paired and unpaired), ANOVA (Analysis of Variance) followed by Bonferroni post hoc test. The limit of significance was set at $\mathrm{p}<0.05$.

\section{Results}

\section{Effect of Carietinu mextract on the body weight of nSTZ} diabetic rats

Table 1 shows the effect of $C$. arietinum seed extract on body weight of type 2 diabetic model rats during 28 days of chronic administration. Body weight of each rat was taken at seven days interval. As it is seen from the Figure 1 a gradualincrease of body weight was observed in CA Ext 1 treated group. In all other groups i.e., water control, glibenclamide and CA Ext 2 treated groups a nonsignificant fall in body weight was noticed in the $1^{\text {st }}$ week of the experimental period and after that an 
Citation: Bhowmik A, Mossihuzzaman M, Kabir Y, Rokeya B (2016) Glycemic, Insulinemic, Lipidemic and Antioxidant Status of nSTZ Rats after Chronic Administration of Cicer arietinum Extract. Metabolomics (Los Angel) 6: 179. doi:10.4172/2153-0769.1000179

Page 3 of 7

increase was noticed in body weight which was also not significant in any group.

\section{Effect on glucose homeostasis}

Fasting Serum Glucose (FSG) levels of nSTZ diabetic rats of 4 experimental groups were almost similar on 0 day (Figure 2). After oral administration of respective treatment to the type 2 diabetic model rats of different groups for 28 days of experimental period, it was found that the FSG level of all the groups of rats decreased however the decrease was not significant except for CA Ext 2 group. The nSTZ diabetic rats treated with CA Ext $2(\mathrm{p}=0.049)$ showed a significant decrease while comparing within group respectively. As expected, glibenclamide also ameliorated the diabetic condition on $28^{\text {th }}$ day.

\section{Effect on serum insulin level}

Table 1 demonstrates the effect of $C$. arietinum extract on fasting serum insulin level of nSTZ diabetic rats. It is seen that serum insulin level decreased in all the groups except CA Ext 2 treated group which showed $32 \%$ increase compared to baseline value. However the increase was not significant.

\section{Effect of C. arietinum on HOMA B\%, HOMA S\% and HOMA IR of nSTZ diabetic rats}

Table 2 represents the results of 28 days treatment of nSTZ diabetic with C. arietinum. CA Ext 1 showed a $30 \%$ increase in beta cell function

\begin{tabular}{|c|c|c|}
\hline \multirow{2}{*}{ Groups } & \multicolumn{2}{|c|}{ Insulin (picomol/l) } \\
\cline { 2 - 3 } & $\mathbf{0}$ day & $\mathbf{2 8}$ day \\
\hline WC $(\mathbf{n}=\mathbf{7})$ & $85.37 \pm 53.23(100 \%)$ & $79.81 \pm 71.46(93 \%)$ \\
\hline Gliben $(\mathbf{n}=7)$ & $78.87 \pm 53.10(100 \%)$ & $67.59 \pm 41.33(85 \%)$ \\
\hline CA Ext 1 $(\mathbf{n}=\mathbf{8})$ & $89.72 \pm 68.37(100 \%)$ & $118.20 \pm 71.51(132 \%)$ \\
\hline CA Ext 2 $(\mathbf{n}=\mathbf{8})$ & $77.68 \pm 28.92(100 \%)$ & $39.13 \pm 19.26(50 \%)$ \\
\hline
\end{tabular}

Table 1: Chronic effect of $C$. arietinum extract on fasting serum insulin level of nSTZ diabetic rats.

Results are expressed as Mean $\pm \mathrm{SD}$. Between groups, comparison was done using one way ANOVA with post hoc Bonferroni test and within groups, comparison was done using paired $t$ test
(HOMA B\%) and 17\% decrease in insulin resistance (HOMA IR) when compared with the initial day value. HOMA B\% remained unchanged in CA Ext 1 treated and Glibenclamide treated groups. Insulin sensitivity (HOMA S\%) was found to be increased by $32 \%$ and $11 \%$ by the treatment of Ext 2 and glibenclamide treated groups respectively. Insulin resistance index HOMA IRwas decreased by $30 \%$ and $70 \%$ in CA Ext $2(\mathrm{p}<0.05)$ and glibenclamide treated groups respectively on $28^{\text {th }}$ day in comparison to 0 day value.

\section{Effect of $C$. arietinum on the serum Lipid profile of $\mathrm{nSTZ}$ diabetic rats}

Figure 3 depicts the effect of $C$. arietinum on the serum Lipid profile of nSTZ diabetic rats.

Treatment of diabetic model rats for 28 days with CA Ext 2 resulted in a significant decrease $(\mathrm{p}=0.014)$ in serum cholesterol level when compared with water control. A rapid decreased was shown in CA Ext 1 group on final day in comparison to water control but the level was out of significant $(\mathrm{p}=0.007)$ and a significant $(\mathrm{p}=0.033)$ decrease was noticed in glibenclamidetreated group on 28 day in comparison to water control value. The triglyceride levels were decreased by $11 \%$ in CA Ext 1 group on the final day compared to baseline value, however the fall in TG level was insignificant. Serum HDL was increased by $4 \%$ in CA Ext 1 treated group. LDL-cholesterol levels were remained unchanged among all ofthe groups under study.

\section{Chronic effect of Carietinum on Liver and kidney function}

As it is seen from Table 3 serum ALT level was increased by $32 \%$ and decreased by $30 \%$ in CA Ext 1 and CA Ext 2 treated groups respectively on final day incomparison to 0 day value, however, the change was not statistically significant. Regarding serum creatinine level no significant change was noticed in any group of nSTZ rats.

\section{Effects on hepatic glycogen content}

The chronic effects of Carietinum extract on hepatic glycogen content (on fasting condition) of nSTZ diabetic rats after 28 days of

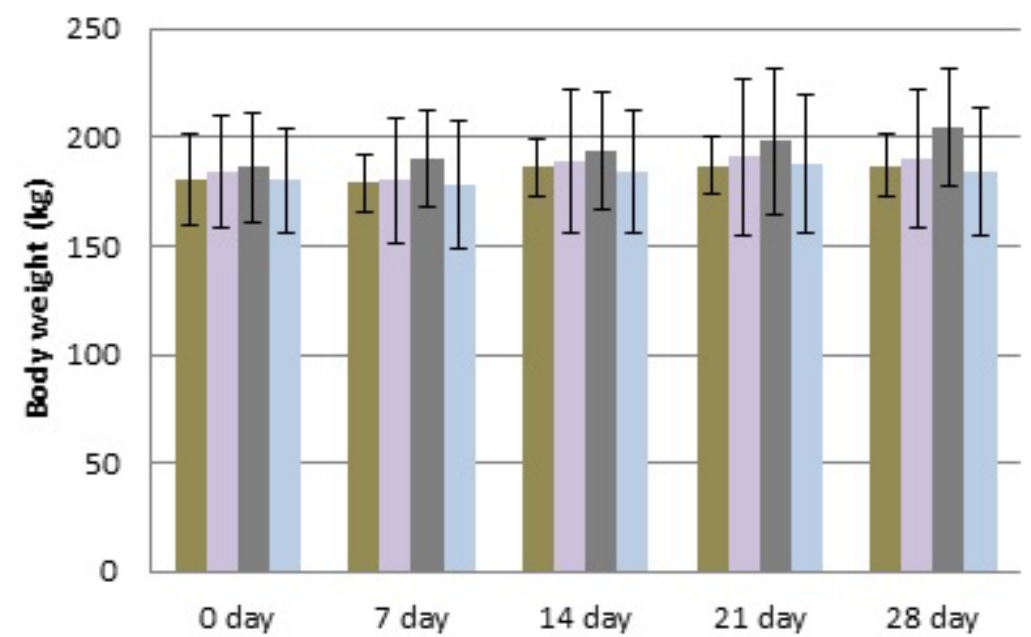

Time duration
Water control

Gliben

- CA Ext 1

- CA Ext 2

Figure 1: Effect of $C$. arietinum extract on the body weight of nSTZ diabetic rats 
Citation: Bhowmik A, Mossihuzzaman M, Kabir Y, Rokeya B (2016) Glycemic, Insulinemic, Lipidemic and Antioxidant Status of nSTZ Rats after Chronic Administration of Cicer arietinum Extract. Metabolomics (Los Angel) 6: 179. doi:10.4172/2153-0769.1000179

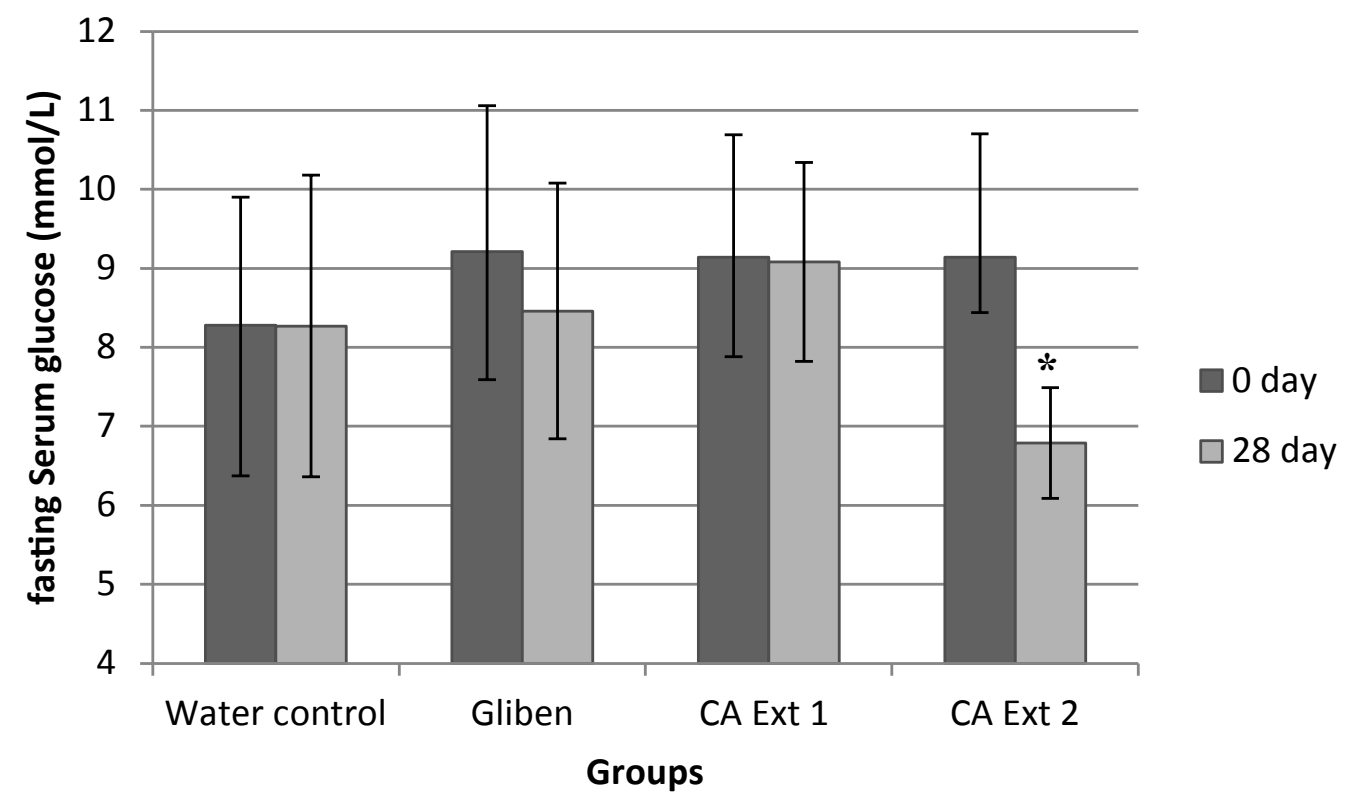

Figure 2: Chronic effect of $C$. arietinum extracts on Fasting Serum Glucose (FSG) level of nSTZ diabetic rats. Results are expressed as Mean \pm SD. Between groups, comparison was done using one way ANOVA with post hoc Bonferroni test and within groups, comparison was done using paired $t$ test. $A=C A$ Ext 2,0 day vs. 28 day

120

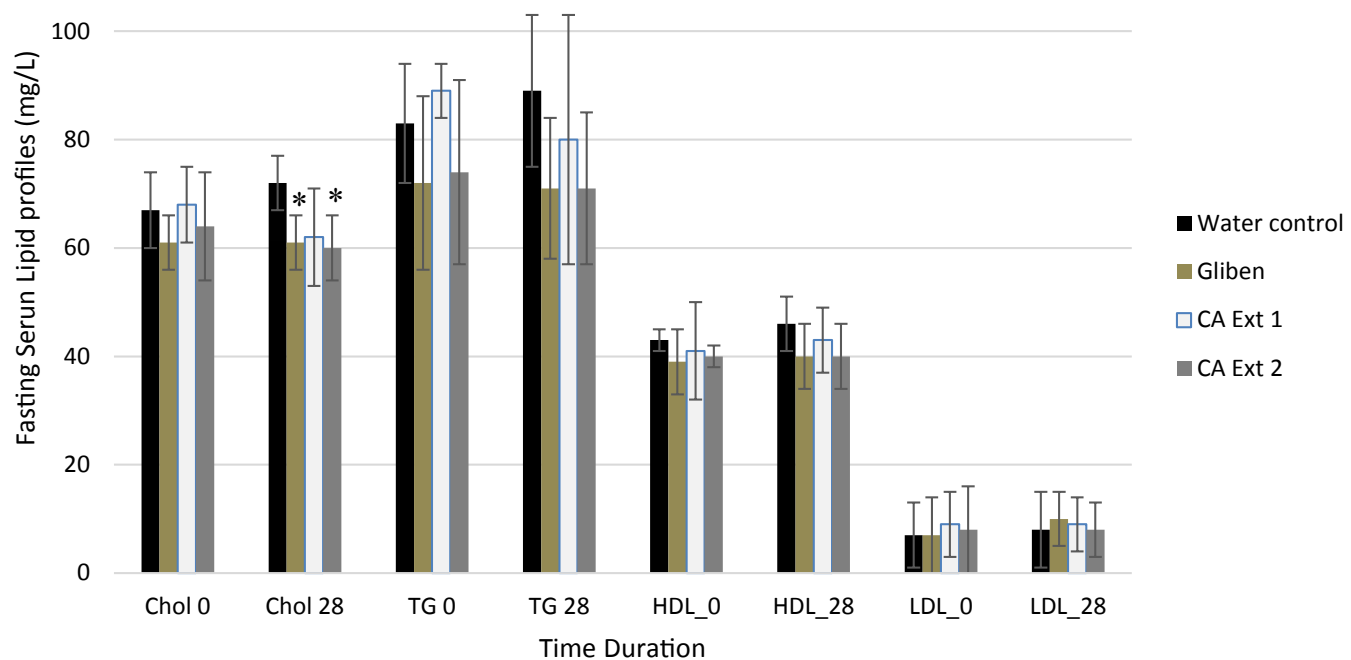

Figure 3: Effects of $C$. arietinum on total serum lipid profiles of nSTZ diabetic rats.

Results are expressed as Mean \pm SD. Between groups, comparison was done using one way ANOVA with post hoc Bonferroni test and Within groups, comparison was done using paired $t$ test. a=CA Ext 2,0 day vs. 28 day

chronic treatment is presented in Figure 4. It is clear from the Figure 4 that there were no significant changes in hepatic glycogen content among glibenclamide and CA Ext 2 treated group; but $51 \%$ increased $(\mathrm{p}=\mathrm{ns})$ was shown in CA Ext 1 group after 28 days of oral administration when it was compared with water control.

\section{Effect of C. arietinum on antioxidative enzymes}

Figure 5 shows the concentration of erythrocyte lipid peroxidation products i.e., Malondialdehyde (MDA) and reduced Glutathione (GSH) in different groups of rats after 28 days of the study period. The levels of erythrocyte MDA were lowerd by 5\% in CA Ext 2 in comparison to water control group. CA Ext 1 showed a significant increase in Reduced-GSH levels when it was compared with water control $(\mathrm{p}=0.031)$. However, there was an $8 \%$ increase in erythrocyte MDA level compared to control group. 
Citation: Bhowmik A, Mossihuzzaman M, Kabir Y, Rokeya B (2016) Glycemic, Insulinemic, Lipidemic and Antioxidant Status of nSTZ Rats after Chronic Administration of Cicer arietinum Extract. Metabolomics (Los Angel) 6: 179. doi:10.4172/2153-0769.1000179

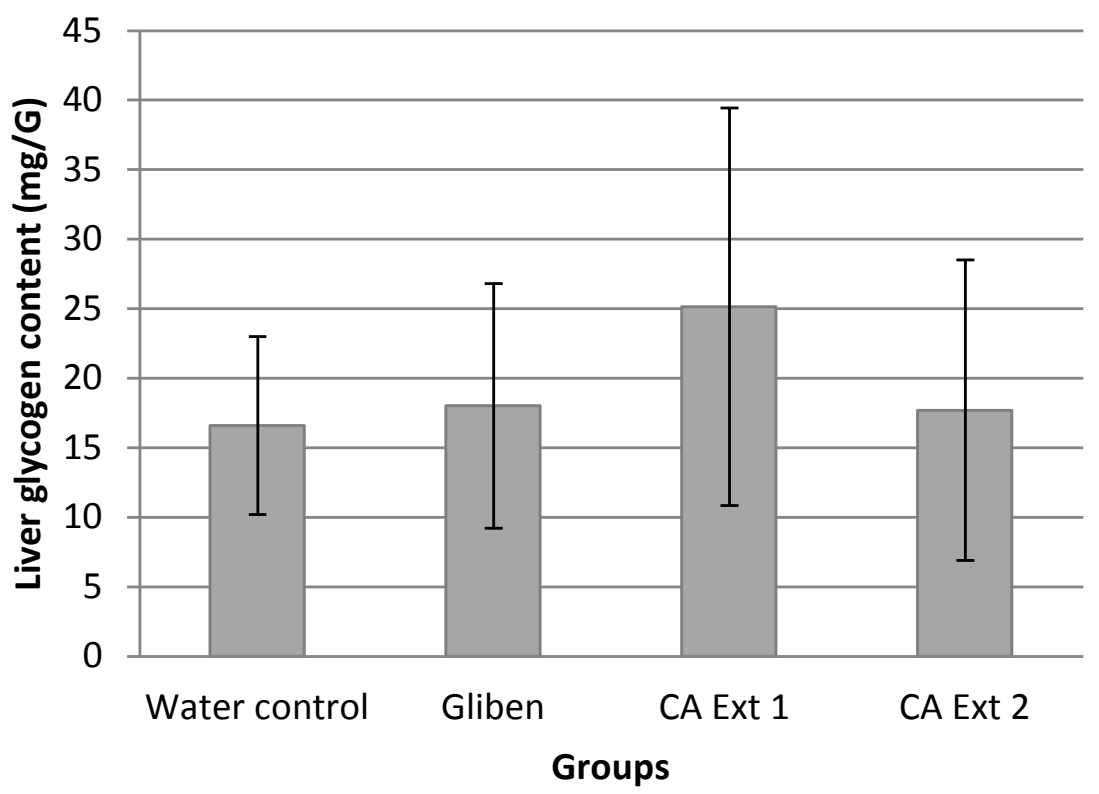

Glycogen

Figure 4: Effect of $C$. arietinum on hepatic glycogen content of nSTZ diabetic rats.

Results are expressed as Mean \pm SD. Between groups, comparison was done using one way ANOVA with post hoc Bonferroni test and within groups, comparison was done using paired t test

\begin{tabular}{|c|c|c|c|c|c|c|}
\hline \multirow{2}{*}{ Groups } & \multicolumn{2}{|c|}{ HOMA B\% } & \multicolumn{2}{|c|}{ HOMA S\% } & \multicolumn{2}{|c|}{ HOMA IR } \\
\hline & 0 day & 28 day & 0 day & 28 day & 0 day & 28 day \\
\hline $\begin{array}{l}\text { WC } \\
(n=7)\end{array}$ & $\begin{array}{c}48.02 \pm 21.22 \\
(100 \%)\end{array}$ & $\begin{array}{c}49.26 \pm 19.10 \\
(102 \%)\end{array}$ & $\begin{array}{c}121.09 \pm 99.72 \\
(100 \%)\end{array}$ & $\begin{array}{c}128.27 \pm 118.00 \\
(105 \%)\end{array}$ & $\begin{array}{c}4.7 \pm 3.5 \\
(100 \%)\end{array}$ & $\begin{array}{c}10.9 \pm 13.9 \\
(231 \%)\end{array}$ \\
\hline $\begin{array}{c}\text { Gliben } \\
(n=7)\end{array}$ & $\begin{array}{c}39.98 \pm 14.73 \\
(100 \%)\end{array}$ & $\begin{array}{c}42.23 \pm 22.69 \\
(105 \%)\end{array}$ & $\begin{array}{l}92.41 \pm 85.59 \\
(100 \%)\end{array}$ & $\begin{array}{c}106.05 \pm 79.11 \\
\quad(111 \%)\end{array}$ & $\begin{array}{c}5.5 \pm 3.4 \\
(100 \%)\end{array}$ & $\begin{array}{c}3.9 \pm 2.8 \\
(70 \%)\end{array}$ \\
\hline $\begin{array}{c}\text { CA Ext } 1 \\
(n=8)\end{array}$ & $\begin{array}{c}42.03 \pm 9.24 \\
(100 \%)\end{array}$ & $\begin{array}{c}52.00 \pm 16.68 \\
(123 \%)\end{array}$ & $\begin{array}{l}65.15 \pm 45.16 \\
(100 \%)\end{array}$ & $\begin{array}{c}64.90 \pm 43.79 \\
(99 \%)\end{array}$ & $\begin{array}{c}6.6 \pm 4.3 \\
(100 \%)\end{array}$ & $\begin{array}{c}5.5 \pm 3.6 \\
(83 \%)\end{array}$ \\
\hline $\begin{array}{c}\text { CA Ext } 2 \\
(n=8)\end{array}$ & $\begin{array}{c}43.15 \pm 12.48 \\
\quad(100 \%)\end{array}$ & $\begin{array}{c}43.55 \pm 43.78 \\
(100 \%)\end{array}$ & $\begin{array}{c}74.45 \pm 68.36 \\
(100 \%)\end{array}$ & $\begin{array}{l}125.18 \pm 54.65 \\
\quad(168 \%)\end{array}$ & $\begin{array}{c}6.0 \pm 4.3 \\
(100 \%)\end{array}$ & $\begin{array}{c}1.8 \pm 1.3 \\
(30 \%) \\
p=0.052 a\end{array}$ \\
\hline
\end{tabular}

Table 2: Effect of $C$. arietinum on HOMA B\%, HOMA S\% and HOMA IR of nSTZ diabetic rats.

Results are expressed as Mean \pm SD. Between groups, comparison was done using one way ANOVA with post hoc Bonferroni test and within groups, comparison was done using paired $t$ test. a=CA Ext 2, 0 day vs. 28 day.

\begin{tabular}{|c|c|c|c|c|}
\hline \multirow{2}{*}{ Groups } & \multicolumn{2}{|c|}{ ALT (U/L) } & \multicolumn{2}{c|}{ S Creatinine (mg/dl) } \\
\cline { 2 - 5 } & $\mathbf{0}$ day & $\mathbf{2 8}$ day & 0 day & $\mathbf{2 8}$ day \\
\hline \multirow{2}{*}{ WC (n=7) } & $\begin{array}{c}64 \pm 37 \\
(100 \%)\end{array}$ & $\begin{array}{c}91 \pm 51 \\
(142 \%)\end{array}$ & $0.77 \pm 0.11$ & $0.79 \pm 0.09$ \\
\hline Gliben (n=7) & $\begin{array}{c}62 \pm 22 \\
(100 \%)\end{array}$ & $\begin{array}{c}93 \pm 26 \\
(147 \%)\end{array}$ & $0.73 \pm 0.14$ & $0.83 \pm 0.18$ \\
\hline CA Ext 1 (n=8) & $\begin{array}{c}65 \pm 15 \\
(100 \%)\end{array}$ & $\begin{array}{c}86 \pm 8 \\
(132 \%)\end{array}$ & $0.73 \pm 0.09$ & $0.81 \pm 0.13$ \\
\hline CA Ext 2 (n=8) & $\begin{array}{c}101 \pm 84 \\
(100 \%)\end{array}$ & $\begin{array}{c}71 \pm 18 \\
(70 \%)\end{array}$ & $0.80 \pm 0.08$ & $0.76 \pm 0.05$ \\
\hline
\end{tabular}

Table 3: Chronic effect of extract of $C$. arietinum on liver and kidney function of nSTZ diabetic rats.

Results are expressed as Mean $\pm \mathrm{SD}$. Between groups, comparison was done using one way ANOVA with post hoc Bonferroni test and within groups, comparison was done using paired $t$ test

\section{Discussion}

Oral hypoglycemic agents and insulin is the mainstay of treatment of diabetes and are effective in controlling hyperglycemia, however, they have prominent side effects and fail to significantly alter the course of diabetic complications [21]. As the knowledge of heterogeneity of this disorder increases, it is needed to look for more efficacious agents

with lesser side effects. Though the development of modern medicine results in the advent of modern pharmacotherapeutics (in additions to insulin, sulphonylureas and biguanides, hiazolidinediones) like DPPIV inhibitors, Glucagon like peptides etcthere is still a need to look for new drugs as the existing drugs do not modify the course of diabetic complications. Therefore, as the disease is progressing unabated, there is an urgent need of identifying indigenous natural resources with antidiabetic properties in order to develop them as new therapeutics.

The present study was undertaken to assess the antidiabetic effect with underlying mechanism of action of $C$. arietinum extract on $\mathrm{nSTZ}$ diabetic model rats. C. arietinum extract with two different doses were fed to diabetic rats for 28 consecutive days. It was found that the nSTZ diabetic rats from all groups gained in body weight throughout the experimental period which was also observed by other investigators [14,22-24].

Ethanol extract of C. arietinum lowered serum glucose level significantly on $28^{\text {th }}$ day $(\mathrm{p}=0.049)$. The possible mechanism underlying the hypoglycemic activity of extract may be potentiation of pancreatic secretion of insulin from $\beta$-cell coupled with extra pancreatic 
Citation: Bhowmik A, Mossihuzzaman M, Kabir Y, Rokeya B (2016) Glycemic, Insulinemic, Lipidemic and Antioxidant Status of nSTZ Rats after Chronic Administration of Cicer arietinum Extract. Metabolomics (Los Angel) 6: 179. doi:10.4172/2153-0769.1000179

Page 6 of 7

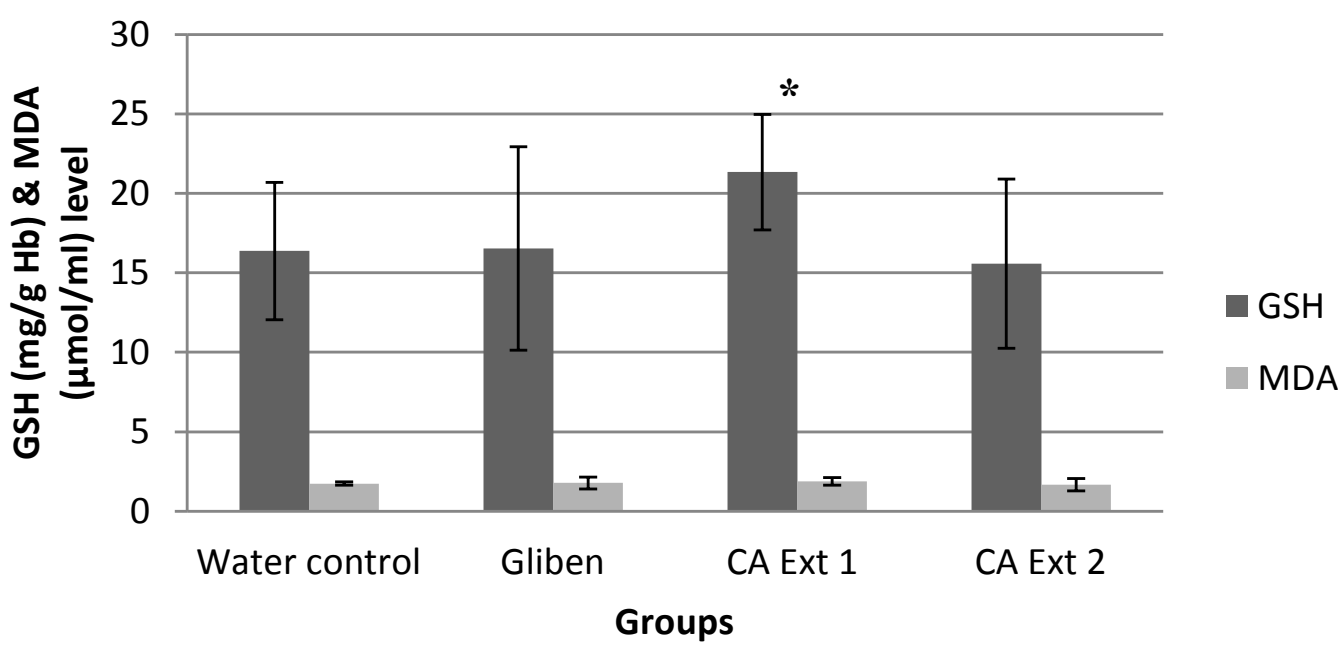

Figure 5: Effects of $C$. arietinum on serum Malondialdehyde (MDA) and reduced Glutathione (GSH) of nSTZ diabetic rats. Results are expressed as Mean \pm SD. Between groups, comparison was done using one way ANOVA with post hoc Bonferroni test and within groups, comparison was done using paired $t$ test.

mechanisms like decreased glycogenolysis and enhanced glycogenesis by the liver. When serum insulin level was investigated it was found that the obtained results showed that $C$. arietenum in the low dose $(0.625$ $\mathrm{mg} / \mathrm{kw} \mathrm{bw})$ increased serum insulin level but the higher dose $(1.25 \mathrm{~g} / \mathrm{kg}$ bw) did the opposite effect. Interestingly, when B cell secretion (HOMA B\%), insulin sensitivity (HOMA S\%) and Insulin resistance (HOMA IR) were determined by using HOMA-SIGMA software it was found that $C$. arietenum at higher dose (CA Ext 2) improve insulin sensitivity and insulin resistance. These effects in turn can lower blood glucose level and can thereby decrease the requirement for insulin. Therefore, it is speculated that the observed improvement in insulin sensitivity and insulin resistance was responsible for glucose and insulin lowering effect of CA Ext 2 treated group.

Type 2 diabetes is associated with marked imbalance in lipid metabolism [25]. The association of hyperglycemia with an alteration of lipid parameters presents a major risk for cardiovascular complications in diabetes. In the present study, effect of C. arietinum extract on lipid profile was evaluated after 28 days of chronic administration and $C$. arietinum at $1.25 \mathrm{~g} / \mathrm{kg}$ bw caused a significant decrease $(\mathrm{p}=0.014)$ in serum cholesterol level when compared with water control. Serum HDL-cholesterol increased nonsignificantlyin extract treated group in comparison to the base line level. The findings are in concordance with other investigators $[26,27]$

Serum alanine amino transferase (ALT) is considered more specific for hapatocellular damage. Serum ALT level was decreased by $30 \%$ (nonsignificantly) in CA Ext 2 treated group on final day in comparison to 0 day value. Renal excretory function can be assessed by measuring serum creatinine levels. In this study after 28 days consecutive feeding of C. arietinumserum creatinine level almost remained unchanged which means that $C$. arietinum has no toxic effect on liver and kidney function.

Liver glycogen level may be considered as the best marker for assessing hypoglycemic activity of any drug. Increased liver glycogen level was observed in extract treated group. Therefore, it may be ascertained that the hypoglycemic activity of $C$. aritenum in type 2 model rats is due to increased uptake of glucose for the formation of glycogen by enhanced glycogenesis. This may be one of the probable mechanisms for the hypoglycemic action. There is a clearly documented link between diabetic complications and lipid peroxidation. Hypoinsulinemia increases the activity of the enzyme, fatty acyl-CoA oxidase that initiates $\beta$-oxidation of fatty acids. This results in lipid peroxidation, which is determined by thiobarbituric acid (TBAR) substances level. In our experiment, the MDA level was decreased when treated extract of $C$. aritenum compared with vehicle group [26]. Our result showed a significant increase in the GSH level, when treated with extract CA Ext 1 . The obtained findings also correlate with the findings of other scientists [27-29].

\section{Conclusion}

It may be concluded that ethanolic extract $C$. arietinum at higher dose $(1.25 \mathrm{~g} / \mathrm{kg} \mathrm{bw})$ showed significant hypoglycemic and antilipidemic effects most likely through decreasing insulin resistance and improving insulin sensitivity. It also has antioxidant activity that reduces the oxidative changes induced by STZ administration.

\section{Acknowledgement}

We gratefully acknowledge the financial support of International Program for the Chemical Sciences (IPICS), Uppsala, Sweden; and Asian Network of Research on Antidiabetic plants (ANRAP) in conducting this study.

\section{Authors' Contributions}

\begin{tabular}{|l|c|c|c|c|}
\hline Authors' contributions & AB & MM & YK & BR \\
\hline Research concept and design & $\checkmark$ & $\checkmark$ & $\checkmark$ & $\checkmark$ \\
\hline Collection and/or assembly of data & $\checkmark$ & -- & -- & -- \\
\hline Data analysis and interpretation & $\checkmark$ & -- & -- & $\checkmark$ \\
\hline Writing the article & $\checkmark$ & -- & -- & -- \\
\hline Critical revision of the article & $\checkmark$ & -- & -- & $\checkmark$ \\
\hline \multicolumn{1}{|c}{ Final approval of article } & $\checkmark$ & $\checkmark$ & $\checkmark$ & $\checkmark$ \\
\hline Financial and Logistic supports & -- & $\checkmark$ & -- & $\checkmark$ \\
\hline Statistical analysis & $\checkmark$ & -- & -- & $\checkmark$ \\
\hline
\end{tabular}


Citation: Bhowmik A, Mossihuzzaman M, Kabir Y, Rokeya B (2016) Glycemic, Insulinemic, Lipidemic and Antioxidant Status of nSTZ Rats after Chronic Administration of Cicer arietinum Extract. Metabolomics (Los Angel) 6: 179. doi:10.4172/2153-0769.1000179

\section{References}

1. Ghosh S, Suryawanshi SA (2001) Effect of Vincarosea extracts in treatment of alloxan diabetes in male albino rats. Indian Journal of Experimental Biology 39: $748-759$

2. Ladeji O, Omekarah I, Solomon M (2003) Hypoglycemic properties of aqueous bark extract of Ceibapentandra in streptozotocin-induced diabetic rats. Journal of Ethnopharmacology 84: 139-142.

3. Geetha BS, Biju CM, Augusti KT (1994) Hypoglycemic effect of leucodelphidin derivative isolated from Ficusbengalensis (Linn.). Indian Journal of Pharmacology 38: 220-222

4. Rao BK, Sudarshan PR, Rajasekhar MD, Nagaraju N, Rao CA (2003) Antidiabetic activity of Terminaliapallida fruit in alloxan-induced diabetic rats. Journal of Ethnopharmacology 85: 169-172.

5. Vats V, Grover JK, Rathi SS (2002) Evaluation of antihyperglycemic effect of Trigonellafoenum-graecum Linn. Occium sanctum Linn and Pterocarpusmarsupium Linn, in normal and alloxanised diabetic rats. Journal of Ethnopharmacology 79: 95-100.

6. Amrita B, Liakot AK, Masfida A, Begum R (2009) Studies on the antidiabetic effects of Mangiferaindica stem-barks and leaves on nondiabetic, type 1 and type 2 diabetic model rats. Bangladesh J Pharmacol 4: 110-114.

7. Chakrabarti S, Biswas TK, Seal T, Rokeya B, Ali L, et al. (2005) Antidiabetic activity of Caesalpiniabonducella F. in chronic type 2 diabetic model in Long Evans rats and evaluation of insulin secretagogue property of its fractions on isolated islets. J Ethnopharmacology 97: 117-122.

8. Gautam M, Anamika G (2012) Antihyperglycemic and antioxidant potential of Murrayapaniculata Linn. Leaves: A preclinical study. J of Pharmacy Research 2: $1334-1337$

9. Priyabrata P, Pritishova B, DEbajyoti D, Sangram KP (2010) Ocimum Sanctum Linn, A reservoir plant for therapeutic applications: An Overview. Pharmacogn Rev 4: 95-105.

10. Thamilvaani M, Uma DP, Cheng HM (2012) Tropical Plant Extracts as Potential Antihyperglycemic Agents. Molecules 17: 5915-5923.

11. Gandhi GR, Savarimuthu I, Michael GP (2011) Salanum torvum Swartz. Fruit containing phenolic compounds shows antidiabetic and antioxidant effects in Streptozotocin induced diabetic rats. Food Chem Toxicol 49: 2725-2733.

12. Saha S, Verma R (2012) Inhibitory potential of traditional herbs on alphaamylase activity. Pharm Biol 50: 326-331.

13. Jukanti AK, Gaur PM, Gowda CL, Chibbar RN (2012) Nutritional quality and health benefits of chickpea (Cicer arietinum L): A review. Br J Nutr 108: 11-26.

14. Mao X, Zhang L, Xia Q, Sun Z, Zhao X, et al. (2008) Vanadium-enriched chickpea sprout ameliorated hyperglycemia and impaored memory in STZ induced diabetes rats. BioMetals 21: 563-570.
15. Johnson SK, Thomas SJ, Hall RS (2005) Palatability and glucose, insulin and satiety responses of chickpea flour and extruded chickpea flour bread eaten as part of a breakfast. European J Clinical Nutrition 59: 169-176.

16. Bonner Weir S, Trent DF, Honey RN, Weir GC (1981) Response to neonata rat islets to streptozotocin. Limited $\beta$-cell regeneration and hyperglycemia. Diabetis 30: 64-69.

17. Friedewald T, Levy RI, Frederickson DS (1972) Estimation of the concentration of low density lipoprotein cholesterol in plasma, without use of the preparative ultracentrifuge. Clin Chem 6: 499-503.

18. Mathews DR, Hosker JP, Rudenski AS, Naylor BA, Teacher DF, et al. (1985) Homeostasis model assessment: insulin resistance \& B-cell function from fasting plasma glucose and insulin concentration in man. Diabetologia 28: 412 419 .

19. Ellman GL (1959) Determination of sulfhydryl group. Arch Biochem Biophys 82: 70-74.

20. Srour MA, Bilto YY, Juma M, Irhimeh MR (2000) Exposure of human erythrocytes to oxygen radicalscauses loss of deformability, increased osmotic fragility lipid peroxidation and protein degradation. Clin Haemorheol Microcirc 23: $13-21$

21. Rang HP, Dale MM, Rittar JM (1991) The endocrine system Pharmacology. In Pharmacology. Longman Group Ltd., UK, pp: 504-508.

22. Yadav BV, Deshmukh TA, Badole SL, Kadam HM, Bodhankar SL, et al. (2009) Antihyperglycaemic activity of cicerarietinum seeds. Pharmacologyonline 3 748-757.

23. Tiwari AK, Praveen Kumar M, Anand Kumar D, Agawane SB, Madhusudana K et al. (2012) Ayurvedic dietary formulations and postprandial glycemia in rats International Food Research Journal 19: 765-773.

24. Panlasigui LN, Panlilio LM, Madrid JC (1995) Glycaemic response in norma subjects to five different legumes commonly used in the Philippines. Int J Food Sci Nut 46: 155-160.

5. Gadi R, Samehe FF (2007) Dyslipideia in type 2 diabetes mellitus. Curr Diab Rep 7: 228-234

26. Horie S, Ishii H, Suga T (1981) Changes in peroxisomal fatty acid oxidation in the diabetic rat liver. J Biochem 90: 1691-1696.

27. Harini S, Adilaxmamma K, Mohan EM, Srilatha C, Raj MA (2015) Antihyperlipidemic activity of chickpea sprouts supplementation in ovariectomyinduced dyslipidemia in rats. J Ayurveda Integr Med 6: 104-110.

28. Orona VU, Oros JH, Millán EC (2010) Component Analysis and Free Radicals Scavenging Activity of Cicerarietinum L Husk Pectin. Molecules 15: 6948-6955.

29. Prathapan A, Fahad K, Thomas BK, Philip RM, Raghu KG (2011) Effect of sprouting on antioxidant and inhibitory potential of two varieties of Bengal gram (Cicerarietinum L.) against key enzymes linked to type-2 diabetes. International Journal of Food Sciences and Nutrition 62: 234-238. 